\title{
Participatory Design as the Temporal Flow of Coalescing Participatory Lines
}

\author{
Niall Hayes ${ }^{1 *}$ (1), Lucas D. Introna ${ }^{1} \&$ Noel Cass $^{2}$ \\ *1 Department of Organisation, Work and Technology, Lancaster University, Lancaster, LA14YX, UK ( \\ E-mail:n.hayes@lancaster.ac.uk; E-mail:l.introna@lancaster.ac.uk); ${ }^{2}$ Institute for Transport Studies, \\ Leeds University,Leeds, LS29JT, UK (E-mail: n.f.cass@leeds.ac.uk)
}

Accepted: 17 June 2021

\begin{abstract}
This paper argues that the existing literature on participatory design (PD) tends to focus on frontstage design interactions (workshops, participants, methodologies, techniques, etc.) to facilitate PD 'here and now' - referred to as the interactional approach. In contrast, the paper proposes to contribute to an evolving literature, referred to as the transformational approach, that takes a more longitudinal line and which attends to both the frontstage and backstage within an extended temporal frame. To do this the paper draws on the work of the social anthropologist Tim Ingold, in particular, his concept of the happening of ongoing life as a bundle of flowing lines. The paper argues that PD becomes possible when ongoing participation is conceived of as a set of corresponding (or coalescing) and conditioning lines of flow - each line with its own history, attentionality, rhythms, tempos and so forth. To illustrate what this reorientation might mean for PD the paper draws on an in-depth action research study of a PD initiative that sought to develop a digital service to address loneliness and social isolation in a rural location in the UK. The paper explores how project members, individual participants, non-governmental organisation, government representatives, evaluators and funders co-responded to each other (or not) as they engaged, or became implicated, in the PD process. The paper concludes with some practical implications of what such an Ingoldian reorientation might mean for the ongoing development of PD as a transformational methodology.
\end{abstract}

Keywords: Ingold, participatory design, Temporality, Conditioning flow, Correspondence

\section{Introduction}

Participatory design (PD) has a long history in the development of information and communication technologies (ICT) and in the computer supported cooperative work (CSCW) literature specifically (Simonsen and Robertson 2012; Suchman 2002). Proponents of PD commit to designing a (digital) service with potential future users and stakeholders (Bratteteig and Wagner 2016; Kensing 2003). They seek to encourage participation through a wide variety of roles such as technical experts, facilitators, public participants and/or stakeholders throughout the design process (Martin et al. 2009). A PD cycle typically involves exploring problem situations, understanding practice, identifying needs, describing requirements, developing 
technology, and then testing the technology (Bratteteig et al. 2013). Designing with future users is claimed to result in outcomes that are better suited to their future context of use (Ehn 2008). PD perspectives thus seek to provide ways for users and other stakeholders to have a say in the design process and therefore, in the intended outcome (Bratteteig et al. 2013). Other commentators view participation in the design process as being a democratic right for those that might be implicated in the outcomes (Bannon et al. 2018; Bratteteig and Wagner 2014; Smith et al. 2017). This is claimed to lead to stakeholders being supportive of the implementation (Balka 2010; Martin et al. 2009; Simonsen and Robertson 2012).

Studies of PD have their origins in the workplace (Kensing and Blomberg 1998; Shapiro 2005). Consequently, participants tended to be skilled and knowledgeable and had a direct vested interest in improving work conditions for themselves and their team (Dittrich et al. 2003). Further, as access to stakeholders was not especially problematical, it allowed for longitudinal studies (Bratteteig et al. 2013). However, as technology reached out to a wide range of contexts and potential users, this led to a reappraisal of these long-established PD interventions (Bødker 2015). PD projects with the public involving multiple and diverse stakeholders - the focus of this paper - have sought to develop methods that are suitable for public participants such as children, adults, older adults, etc. (Druin and Fast 2002). Unlike in the workplace, public participants often do not have a long term commitment to a project, nor might they have a specific commitment to the intended outcomes. Public participants also use a wide variety of devices at home and while on the move and indeed some might not have used technology at all. Further, studies have highlighted that it is difficult to access and study potential individual participants at home and as they go about their everyday lives (Bratteteig et al. 2013).

PD studies that engage the public are reliant on planned design encounters such as workshops, focus groups and interviews. Informal and observational opportunities are limited. As such, workshops become central as they provide an opportunity for individuals, organisational representatives, and designers to share their experiences (Bødker and Kyng 2018). Cultural probes and diaries have been increasingly used to gain understandings of what issues users consider to be vital and challenging in these distributed settings (Gaver et al. 1999; Loi 2007). Unlike in-situ observational methods, these design-oriented methods garner the perspectives of the different participants at specific points in time as they move through the PD cycle. Workshops are typically staggered across the whole development lifecycle - progressing from problem-solving to technology implementation and testing (Bratteteig et al. 2013). Further, the wide range of individual public participants, as well as stakeholder representatives, means there are a variety of often divergent perspectives involved during PD encounters. It seems evident that this shift in design requirements and context would require a revaluation of how effective participation can be ensured? This is the intention of this paper.

Accordingly, this paper focuses on how we might conceptualise PD processes that primarily engage the public through formal design encounters such as workshops 
over an extended period of time-i.e. multi-stage multi-stakeholder PD projects. To examine this, we consider a PD project-using a co-creation methodology - undertaken with older adults (OA) participants, NGO and government staff in the UK. This project sought to co-create an app with OAs to address their social isolation. Akin to other studies, there was a reliance on design encounters through workshops, interviews and cultural probes. We also consider how the funder's evaluation process was present in design encounters. We locate our orientation within the process tradition in CSCW (Bødker et al. 2017; Karasti et al. 2010; Suchman 2009). In this regard, we ask two related questions: How does one ensure effective participation in the design process when there is a reliance on multiple design encounters over an extended period involving a diversity of stakeholders? And, what might be necessary to join (or weave together) the diversity of experiences and imaginations amongst design participants with potentially divergent interests, temporal frames, and levels of participation?

To respond to these questions, we draw on the work of the social anthropologist Tim Ingold $(2007,2015,2017)$ and argue that PD, in the form suggested, can best be viewed as the weaving together of different lines of participation in a timely manner. More specifically, we suggest the need to take the temporal flow of participation into account more actively. We will argue that to understand the enactment of participation we need to examine how three streams of participation — or flowing lines as we will refer to them - come to correspond (or not): (1) the participants line; (2) the project line; and (3) the process line. This is done in order to understand how the experiences, agendas, and practices of the different participants, such as the design team, OAs, government, and non-governmental organisation staff, flow together (or not) to shape the ongoing PD process and its eventual outcomes.

This paper begins by reviewing the literature on PD. In this review, we argue that when it comes to design with the public - that involves a diversity of stakeholders and happens over an extended period - it is necessary to move from an interactional approach to PD to a transformational approach. We then outline Ingold's work on correspondence and highlight how this will inform our approach to understanding the unfolding of PD, temporally. In section four, we describe the empirical setting and our action research approach. Section five presents a reflective analysis of our PD process. Section six unpacks our discussion of participation being understood as a correspondence of a bundle of lines. The final section will offer some concluding suggestions for how research and practice might attend to the temporal flow of participation in PD projects.

\subsection{Literature review: from interactional PD to transformational PD}

A central question for PD scholars and practitioners is how to facilitate or ensure genuine participation - that is, "the fundamental transcendence of the users' role from being merely informants to being legitimate and acknowledged participants in the design process." (Robertson and Simonsen 2012, p. 5). Below we will consider 
two different traditions of how this can be achieved, what we have labelled as the interactional versus the transformational approaches.

\subsection{Interactional PD: focusing on the here and now of participatory design}

The dominant view in the field is that genuine participation happens in the interactions of design encounters facilitated by effective methods. As such, this literature has tended to focus on the development of methods that seek to facilitate the active and real participation of stakeholders in the analysis and design of systems (Nolte and Herrmann 2016; Branco et al., 2017). This is what Bannon et al. (2018) has referred to as the 'here and now' focus. Likewise, (Bratteteig et al. 2013) argue that much of the research in PD has focussed on developing new methods and techniques to facilitate design interactions. Work here has focussed on how participatory methods such as workshops, prototyping and probes can provide for effective interactional participation. For example, how they can create effective 'third spaces' that are "hybrid space[s] between software professionals and end-users" (Muller 2002). Others, such as Ehn (2008, p. 108) have argued for the creation of a common language game where designers "understand the language-games of the use activity" and users "understand the language-game of design." Similarly, Edwards (2010, p. 64) argued, drawing on activity theory, that effective participation comes from 'relational agency' where designers and users, through their interactions, "expand the 'object of activity' or task being work[ed] on by recognising the motives and the resources that others bring to bear..." and by aligning their responses "to the newly enhanced interpretations" with the responses of the other stakeholders as they act on the expanded object.

Critics have argued that such interactionalist approaches tend to focus their research on participation by prioritising collaboration for a here and now purpose "without much perspective on the future (or for that matter for the past)" (Bødker and Kyng 2018, p. 6). That is, without attending sufficiently to the temporal conditioning of such here and now design interactions. Bannon et al. (2018) claim that this means that the methods are often designer rather than stakeholder-driven. They argue that while this has led to the development of well-refined methods such as probes, toolkits, and role-playing, they seldom account sufficiently for relations of power. Specifically, how such design interactions are often already preconfigured in very significant ways. Moreover, Bannon et al. (2018) criticise much of contemporary work in PD for their focus on developing consumer-oriented methods and on enhancing and professionalising design practices rather than on the more demanding questions of democracy and conflict resolution that are central to the origins of PD.

These charges of being focused on methods and outcomes have led to some to rediscover the empowering and long term relationships that typified the emergence of the field of PD. This is perhaps best encapsulated by Whittle $(2014$, p. 121) who argued that "The charge to the PD community is that participation has become 'a 
goal in itself' and has led to an obsession with methodologies for engendering participation and a willingness to see success in terms of "feel good processes" rather than any long-term, sustained outcome." Implicit in Whittle's critique is that for many focusing on design interactions that feel and do good has become an end in itself. One implication of this is that design interactions are often done with agreeable communities rather than focusing on conflicts tensions and struggles between different user groups and the designers. Indeed, Bødker and Kyng (2018) suggest this might be why there seems to be a contemporary focus on co-creation rather than on PD processes.

\subsection{Transformational PD: creating transformative conditions for participation}

A more recent strand to emerge within the PD literature has adopted a 'transformational' approach. This literature argues for a shift away from the here and now focus towards the production of the necessary conditions for participation to be effective, prior, during and subsequently to design interventions. Effective methods and interactions in the here and now are good and necessary, but we need to understand how the interaction is itself preconfigured prior to the design interactions and also how design outcomes might become embedded in actual practices, subsequently. We will consider two interrelated streams of work in this perspective: (1) infrastructuring, and (2) front staging and back staging.

Infrastructuring traces its origins to Star and Ruhleder's (1996) work on information infrastructure. Karasti (2014) describes infrastructures as interrelated technical, social and organisational arrangements that include not just software and hardware, but also procedures and practices (see also Bødker et al. 2017). Information infrastructures do not just emerge as the outcome of the design process; they are relational and ongoing accomplishments (Neumann and Star 1996). In this sense infrastructures should not be considered to be stable nor should they be assumed to be easily identifiable, bounded and coherent (Jensen and Winthereik 2013). Most accounts to date have drawn on empirical studies to explain how large scale technical infrastructures have evolved over a long time. Indeed, it is this processual (always in the making) as well as longitudinal qualities that led to the coining of the term infrastructuring. (Karasti and Syrjänen 2004).

Research accounts that have focused specifically on infrastructuring in PD - the focus of this paper - have been relatively few. Bødker et al. (2017, p. 246) refers to participatory infrastructuring as all the "activities that engage users in processes of design and use." From the perspective of infrastructuring, $P D$ is a process-orientated accomplishment. As such, PD evolves and unfolds through an ongoing relational becoming. This is what Karasti and Blomberg $(2018$, p. 237) describe as "unfolding the technical, social, political and ethical choices made throughout the design and development of infrastructures." In such unfolding PD, as Mikalsen et al. (2018) highlight, is fundamentally decentred-i.e. it does not have a well-defined or stable locus of control. It does not originate from the designers but emerges through the 
interaction of all stakeholders, designers and technologies, temporally. Likewise, Parmiggiani (2017, p. 208) argues that design is an ongoing process of becoming, and Mikalsen et al. (2018) similarly highlight through the lens of infrastructuring that design is not something fixed from the start but instead is an ongoing transformative becoming. Karasti and Blomberg (2018, p. 238) suggest that as infrastructuring is interwoven and enacted it tends to remain largely invisible, obscure and unremarkable; only becoming visible if there is a breakdown. They go on to argue that there is no single visible hand, no designer that we can attribute causality to, no clear boundaries, no clear roles amongst stakeholders or, areas of expertise, no clear locations for decision-making no coherent language and no shared perspectives. It is always relationally becoming, always in the making - coming from somewhere and going somewhere as it transforms.

As PD has reached out - from the individual to the group, across the workplace, and now to all aspects of society, there are an expanding number of users and different contexts of use (Bødker 2015). Bødker et al. (2017) explore the fluid, relational and increasingly complex nature of participation as ongoing 'knotworking.' Engeström (2008, p. 194) defines knotworking as the "rapidly pulsating, distributed, and partially improvised orchestration of collaborative performance between otherwise loosely connected actors and activity systems.... not reducible to any specific individual or fixed organizational entity as the center of control...[where] The locus of initiative changes from moment to moment within a knotworking sequence." Indeed, Bødker et al. (2017, p. 248) argue that there is a need to provide an account of participatory process "that articulates their reach, the way they tie into existing networks and systems across organisations, and how agency and initiatives become dispersed within these networks." Concerning this expanded relationality and temporality, Parmiggiani (2017, p. 209) suggests that infrastructuring requires us to also consider historical assumptions and anticipated futures. Others have suggested that this processual perspective of PD also allows us to see the subject positions of participants as changing. Crabu \& Magaudda (2018) highlight that we should not look at stakeholders involved in PD as a fixed category of people, but instead we should expect that the subject positions of participants will change throughout.

Some highlight that PD needs to also conceive of possible users beyond those immediately implicated; those in more fluid long term and macro influences that shape the ongoing participatory processes, as Bødker et al. (2017) suggest. To attend to the more vertical and political dimensions of PD, Bødker et al. (2017) bring forward the notions of front stage and backstage design. They highlight how focusing on specific moments of participation fails to attend to the fact that "activities and agency are dispersed both horizontally among the many actors engaged in the process, and vertically through the layers of political authority." (2017, p. 249) and see workshops as the 'front stage' of participation. These are the 'here and now' moments where designers and users for example are collaborating. They argue that front stage design encounters require intense 'backstage' work beforehand, during, 
and afterwards; backstage activities such as meetings, phone calls, and matchmaking that take place outside of the workshop - yet may condition the frontstage practices significantly.

An infrastructuring orientation requires us to attend to ongoing tensions between those that are using and designing the system beyond the here and now design interactions (Parmiggiani 2017). She highlights that through the lens of infrastructure, design should be seen as political as it requires us to work through and think about how power relations are implicated in participatory redesign (Björgvinsson et al. 2010; Mikalsen et al. 2018). Within this literature, some have highlighted that those who design and lead the PD process, subtly shape and configure the design process (Balka, 2010; Bratteteig and Wagner, 2014). They are the ones who have relationships with sponsors, organise the engagement of stakeholders, recruit participants, phrase questions, facilitate participation, manage dissensus and document findings (Bratteteig and Wagner, 2014; Parmiggiani, 2017). Indeed, some literature has suggested that interactions are influenced by the origins and commitments of a project, such as a project proposal (Parmiggiani, 2017; Stirling, 2008). They suggest that these commitments require projects to justify their design approach to external reviewers (Bratteteig and Wagner 2016). Several commentators observe that academic accounts of projects tend to write out backstage work (Bødker et al., (2017). Back staging requires those engaging in (and studying) PD to attend to stakeholders at different organisational and political levels. They argue that the broader political networks are often where certain stakeholders are implicated, directly or indirectly, and where the project may gain leverage or shape outcomes. Attending to the backstage may also reveal tensions between different agendas and might also reveal deliberate efforts at manipulation (Bratteteig and Wagner 2016; Andrew Stirling 2006).

Extending Bødker et al.'s (2017) text slightly, we might suggest that ongoing participation (with often diverging stakeholders) takes place in many different settings at many different times that need to be brought together and changed, somehow. What is less clear from their account is how the front and backstage of participation intertwine and are worked out (or knotted together, to use Bødker's phrase) not only in workshops or in other participatory encounters but also in between (or behind) such encounters. More specifically, we would argue that these situated practice-based studies do not adequately attend to the ongoing and conditioning temporal flow of design participation. By this we do not merely mean time or temporality, more generally, as will become evident below) (Karasti and Syrjänen 2004; Suchman 2002). These two dimensions - of intertwining and ongoing flow of participation - are central to understanding participation as an unfolding multi-stage process involving a diversity of stakeholders with potentially divergent interests, temporal frames, and levels of participation.

Before we move on we want to highlight that we take these two approaches not as oppositional but rather as complimentary. The curation of the interactional 'here and now' in the facilitation of PD interventions are clearly fundamental. However, the 
transformational approach wants to broaden the perspective in order to appreciate that all the actors/actants involved always are already coming from somewhere and are also already heading in some direction. As such a broader temporal frame is necessary to understand the conditions of possibility for participation to become exactly that. To do this we turn to the work of Tim Ingold.

\section{Tim ingold: design as the co-responding lines of flow of participation}

As suggested, the curation of the interaction of stakeholder participants, facilitated by appropriate methods, is important. However, as argued above, given the challenge of a longitudinal multistage multi-stakeholder design process the interactional 'here and now' of participation needs to be looked at within a broader temporal frame. We suggest it requires a shift away from seeing the problem of genuine participation as mostly a 'front stage' problem of methods that facilitate design interactions towards seeing design interactions as the confluence of multiple streams of participatory actions flowing at different speeds from elsewhere, bringing different expectations, and imagining different futures as they flow onwards. Our central claim is that the exclusive focus on the interactional approach tends to be inadequate because it does not attend sufficiently to those entangled forces that already frame and constitute the conditions of possibility of the 'here and now' of design interactions to become effective and meaningful, prior, during and subsequently.

We develop our understanding of the ongoing, entangled, and temporal flow of such participation by drawing on the work of the social anthropologist Tim Ingold (1993, 2015, 2017). More specifically, his notion of the ongoing becoming of life - and in our case participation, more specifically — as flowing lines ${ }^{1}$ of becoming. Ingold argues that to study "things and people are to study the lines they are made of" (p. 5); or flow along as they become. Ingold (2017) argues that every phenomena (or ongoing participatory design practices, in our case) can best be understood as a bundle, or confluence of lines, flowing together to enact it as precisely that. For him the view that in the workshop there are before us a set of already bounded entities (participants, methods, spaces, etc.) that subsequently interact to produce participation (and designed outcomes) is to commit the logic on inversion; an inversion that "turns the pathways along which life is lived into boundaries within which it is enclosed" (Ingold 2011, p. 145). To understand the confluence (or bundling together) of lines in the design workshop we need to

\footnotetext{
${ }^{1}$ In Ingold's vocabulary a 'line' can be thought of as an 'actor' or rather 'actant' in actor network theory terms (Latour 2005). Thus, in a PD workshop a participant (such as a user, facilitator, technologist, etc.), a method (such as a scenario, persona, use case, etc.), or a physical space (such as a room, work space, table, etc.) can each be thought of as an always and already flowing line, or rather bundles of lines, coming from somewhere and flowing somewhere. Thus, what is here and now present in the workshop is just a slice, point, or dot in an extended actively flowing (or becoming) line. To treat as relevant only that which is apparent 'here and now' (a scoop out of the flow) is limiting, according to him.
} 
attend to the conditionality, directionality, and temporal flows of these lines (participants, methods, spaces, etc.).

What we mean by the notion of the conditioning temporal flow of participation is twofold. First, to grasp the conditioning flow of participation is not like observing a sequence of (inter)actions, in a specific workshop space - that is, what actors do as they co-create as part of a design workshop, for example. It is more akin to listening to the flow of a melody or a conversation. The actions of actors - such as playing the notes or saying the words - are necessary. However, the flow of the melody, conversation or participation, emerges through how every sound, meaning, or activity become conditioned by prior, and condition subsequent, sounds, meanings, or activities. This ongoing conditioning flow is what is constitutive of the participation, exactly as participation, rather than merely a bounded sequence of interactional design activities (Ingold 2015). For example, it is not just about a sequence of developing scenarios, personas, use-cases,..., prototypes, and so forth. It is more important to understand how our scenarios frame or configure what is possible to imagine in subsequent steps, and likewise, for every other design intervention - the conditioning flow is as important as the design intervention itself. Second, in the flow of participation, each line (participant, method, space, etc.) has its temporality (directionality, speed, intensity, rhythm, tempo) (Zerubavel 2003) which needs to become 'bundled' or 'knotted' together to correspond meaningfully. We know that for a conversation to work the participants have to 'keep up' with each other and the flow of the conversation in order to make meaningful contributions. Likewise, in the PD process the different lines - often flowing at different speeds - need to be attended to and become knotted together with the appropriate timings for true participation to become possible.

When these flowing lines join or intertwine-one might also say knot together - with each other, they correspond (or co-respond), along lines of flow. Drawing on Dewey (2004), Ingold (2017, p. 15) argues that any participant, in the flow of activity or practice, seeks to correspond by attempting "to cast my experience forward in ways that can join with yours, and you likewise, so that we can

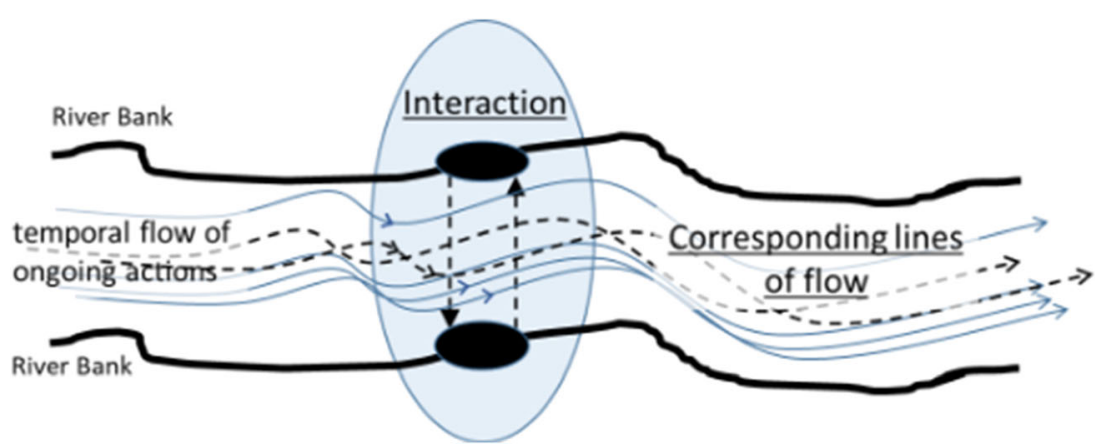

Figure 1. Interaction versus correspondence 
thenceforth travel the same path." In this sense correspondence is orthogonal to interaction. Before exploring the notion of correspondence further, it might be helpful to contrast it with the alternative notions of interaction via the imagery of a flowing river (see Figure 1).

The traditional more interactional approaches start with locating bounded entities here and now in the workshop such as participants, methods, settings, etc. (the located riverbanks) and then seek to understand participation as the interaction between those already separated entities. This interaction is seen as the cause of any changes between them, i.e. of genuine participation. The notion of correspondence, however, suggests that we shift our gaze orthogonally away from frontstage spatial interactional relations between the river banks, towards temporal relations, or co-responsiveness, among ongoing streams of flows, of the river. As such, it specifically brings into focus the different temporal qualities, conditionalities, and directionalities of interweaving co-responsive flows of all stakeholders' ongoing actions prior to, in the 'here and now', and subsequently, as they flow. These corresponding flows achieve what he refers to as a 'like mindedness' that allows for those with different experiences to carry on the participatory practice together - the way that jazz musicians correspond to produce jazz music together. Corresponding does not imply agreement but that the variation between people, as they correspond, will always need to be worked out in the flow, in situ.

Ingold (2017, p. 26/17) highlights that the habitual nature of practices is something that we enact and something we are always inside of - doing it and undergoing it, at the same time. All participants, in their participation, do not choose the manner of their participation as such. Rather, in participating they undergo their habits - that is, their normal manners of doing, thinking, and being-with-others - as they participate. To correspond the participants must become attuned to each other's habitual ways of being to flow together-in the flow of ongoing participation. Treating design practices as interactions between already constituted actors acting together (as is the tendency in the participation literature) is to treat interaction as a process of connecting preexiting participants through design interventions. Correspondence, in contrast, sees the participants as both being in and emerging from, the flow of the participation, as they correspond-i.e. one only becomes a participant in the flow of participating. For this reason, it is important to appreciate both their habitual being as well as their emergent becoming, as they participate. That is, to see them as lines which in their flowing become together as an ongoing rediscovery, but only in and through the flow of participation itself.

Becoming in the flow is also central to understanding attentionality (as opposed to intentionality). Drawing on Manning (2016) Ingold (2017, p. 19) explains that attention "is not consciously directed by an intentional subject, as if shining a spotlight on the world, but is rather emergent in the event, activated by the force of the directionality the event calls forth." In design interventions, there is often an 
emphasis on the intentional methods and methodologies to achieve agreement or consensus in the 'here and now'. However, Ingold would suggest that it is in the ongoing co-responsiveness that the agreement emerges, not about the 'facts' of the design, in the first instance, but rather agreement as attentional likemindedness - which is indeed the condition of possibility for the agreement of the factual design. If this is the case then attending to the attentionality of all participants (or co-responding) is as important as having appropriate methods and methodologies. Moreover, all attentionality is already conditioned by the habitual but also by the 'backstage.' Becoming sensitive to such conditioning allows for a different type of co-responding.

Ingold (2016) explains that becoming mid-stream, in and through the flow, involves both remembering (presencing the past) and imagining (presencing the future). In the flow of design interventions, the past and the future is already active in the present, of PD practice, as it flows (Zerubavel 2003). However, to remember is not to recall some mental content by turning the past into some object in memory. That would suggest that the past is somehow passed (complete and done with). In contrast, Ingold suggests that "[i]n remembering...the past is not finished but active in the present. To remember, in practice, is to re-enter as a correspondent in the processes of one's own and others' development. It is to pick up the threads of past lives and to join with them in finding a way forward" (Ingold 2017, p. 28). In the flow of design activities the participation, exactly as participation, "is itself pregnant with the past." (Ingold 1993). Likewise, imagining does not make an object of the future distinct from the present: "That is to say, it is not to project the future, as a state of affairs distinct from the present." (Ingold 2017, p. 29). As such, Ingold (2017, p. 21) would suggest that in the flow of participation "all imagining is remembering, and all remembering imagining. It is a place we perpetually dream of and strive for, but never reach". In many ways PD practices want to allow participants to imagine that a different future can be designed, or is possible. However, participants, as flowing lines, bring into the workshops their past and this past conditions, sometimes quite significantly, what they might imagine as possible futures (Castoriadis 1997). Thus, it is not just about how backstage configures frontstage - as rightly argued by Bødker et al. (2017) - it is also about attending to the participants' pasts, and allowing them to rediscover the future through that very specific past, which might be very important for co-responding to happen.

To sum up: seen through the Ingoldian lens of correspondence participation becomes enacted as participation through the co-responding of diverse lines flowing, each with its own history, attentionality, rhythms, tempos and so forth. Second, the condition of possibility of participation is not just in the "here and now' interactions but also in the directionality and conditionalities that each of these lines bring along as they flow. Finally, attentionality suggests that the past experiences and future imaginations of each line are active and need to be surfaced and attended to, or co-responded to, in the ongoing flow of participation, midstream as it were. 


\section{Practicing participation: empirical context and methodology}

\subsection{The project}

The project followed an approach inspired by a participatory action research (PAR) methodology (McIntyre 2007). In this approach, there exists "a living dialectical process, changing the researcher, the participants, and the situations in which they act" (McIntyre 2007, p. 1). In other words, the aim of our research project was not just to do the EU funded project and learn something about participation, as a traditional action research project might have done (Taylor et al. 2006). Rather, we were more ambitious. In sympathy with our mostly implicit theoretical orientation, we also wanted to be co-responsive to the becoming of many different lines - the project, the participants, the co-creation process, our partners, ourselves, and so forth.

Practically speaking, the enactment of our PAR methodology consisted of a combination of co-creation workshops together with reflective qualitative methods such as reflective observations, post-workshop debriefings, interviews, and focus groups. The fieldwork was carried out from March 2016 to July 2018 and consisted of 35 interviews, 6 focus groups and 26 co-creation workshops during this period, as well as meetings with local service providers, and 2 user-testing sessions with OAs who did not take part in the co-creation workshops. We also adopted a longitudinal approach in our co-creation workshops, working with the same core group of 7 OAs for over 2 years. Finally, we did a pilot study in partnership with Age UK South Lakeland to trial a scheme where OAs were loaned a tablet containing the co-created Mobile Age Social Connectedness apps. Nine Age UK volunteers took part in this trial. Over 80 people, including OAs, intermediaries (those people such as family, friends, support workers and carers that assisted OAs in accessing mobile technologies and the internet), service providers and researchers participated in the research. Design encounters, such as interviews and workshops, became the modus operandi of the project. As noted in the introduction, PD studies that are undertaken in homes and across organisational boundaries do not benefit from the ease of access and vested interests that those conducted in the workplace do (Bratteteig and Wagner 2016). Observational studies were not possible. As OAs lived independently in their own homes across this rural district, opportunities for them to participate collectively were limited to workshops. As they volunteered, there was no guarantee which OAs would attend each workshop. Further, as we engaged organisational representatives from different government and third sector organisations, workshops were also the only opportunity for them to work collaboratively with each other and with OAs. As they came from different organisations, and it was not clear if any of them would host the co-created service, the vested interests that some PD projects benefit from were not present. Several probes were developed, such as a calendar to try to record what participants did and sought to do each week, some also completed by their friends and neighbours. These probes supplemented the insights that reliance solely on interviews and workshops provided, and were used to feed into subsequent design encounters. 


\subsection{The methodology}

As was suggested, the focus of the co-creation process was not just on co-creating a service. It was also about learning from doing co-creation through a PAR methodology — and we might say, learning by following many lines of flow. As such, we developed systematic practices of in-activity and post-activity reflections - in line with good reflective action research practice (Marshall and Reason 2007). Our goal, initially, was to learn from earlier workshops and use these insights to improve our subsequent practices (workshops, interviews, focus groups, etc.). It was only after some time that we also started to reflect more systematically on informal interactions between the research team and key actors - treating the project more and more as a 'living inquiry' (Marshall 1999). As such, we also started to document all the relevant informal interactions that we had. However, it was only towards the end of the project that we also realised that our focus on lines was perhaps too close-up. Perhaps we should have reflected upon wider aspects of participation, more explicitly; for example, the participation between the team and the wider international project team as well as between the international project team, the funder and reviewer. We will return to this issue in more detail in the discussion below. The lines of becoming that we did follow in our PAR methodology were:

- The co-creation workshops: We designed reflective logs that required one of the research team to document the co-creation process during workshops and the learning arising from that. On-going reflection took place after each workshop hosted and after a series of interviews.

- The app development: The development team met regularly (consisting of developers, some co-creators, and members of the project team). We reflected on the outcomes of the workshops and considered what was learnt and what it might mean for the app development and for how we might run the next workshop.

- The co-creators: We had regular formal and informal interviews (and focus groups) with the co-creators to reflect with them on what they were learning, what did not work for them and how we might improve the process.

- The project: The project team met regularly to reflect on how the project was going, what we had learnt and what it meant for how we moved forward.

- The PAR methodology: We had a regular reflective discussion about our research approach and what we were learning from it, what we needed to change, and so forth.

In a PAR methodology data collection, analysis, and reflection goes hand in hand (McIntyre 2007). Thus, we did not have a separate data analysis phase or step in the methodology. Data was collected, analysed and reflected upon midstream, in the flow, as it happened. As the project evolved, it was very clear to us that the various lines of participation did not always correspond and that we needed to keep our reflective practice open and ongoing to develop co-responsiveness if we wanted the 
participation to be indeed participative. In the next section, we will offer a thematic discussion of some of our findings.

\section{Some key findings: a reflective account of the divergent lines of flow of the project}

This section of the paper will review some of our empirical data. Specifically, we will outline how the different actors participated in the design process.

\subsection{Older adult participants' understanding of technology}

Recruiting OAs to participate as co-creators of digital services was challenging due to their perception of technology. It was difficult to get them to see that their knowledgeability would be fundamental to the development of a digital service. It became apparent in the first few attempts to recruit OAs and in the initial co-creation workshops that many of them resented how services had become digital. For example, face to face service provision across the district had been closed, and call centres had replaced direct telephone lines. They thus saw digitalisation as disrupting their long-established strategies to access public sector services. It became clear that OAs were experts in navigating the specific locale and saw technology as something that could disrupt this local expertise.

One of the things that we had committed to do-as part of the funding requirement-was to develop an 'app.' However, few of our OAs had expertise with technology. They had worked in manual jobs such as farming, manufacturing, or as housewives. As one OA explained:

"Oh, when I came the first few times, I felt I did not know whatsoever of computers and things, and then I sort of found out that I had more knowledge than I thought, and more knowledge than a lot of other people."

Many had no idea what an app was, as an OA co-creator explained:

"I learnt what an app was. You read about them all over the place, but I wasn't sure."

Only one of our participants was an expert user and was confident with apps, websites and video calls. She was a retired teacher and volunteered in an office. This kept her up to date with technology. She lived alone and, as with many of the other longer-term participants was keen to develop relationships with some of the other participants. Co-creation, for OAs, was also seen as an opportunity to address their relative isolation.

The OAs' lack of confidence with regard to technology meant that initially at least, they found it hard to conceive of themselves as experts. Over time, they began to 
realise and also understood that we were designing a digital service that enhanced face to face activities rather than remove them; their key concern with digitalisation. Over time they began to realise that their insights were being picked up in the design of the app; for example, the importance of public transport and the location of benches and toilets. The OAs understood that they were able to articulate their requirements - develop personas that relate to these requirements - and through this become central to the development of a digital service. Importantly, these insights did not emerge in one workshop or at a specific point in time, rather it emerged from how the workshops built upon each other, and how they could see how outcomes from previous design activities became imbedded in subsequent design activities. The OA participants could see this interweaving of the design process:

"when suggestions have been made it is clear at the next session they have been acted upon... [design] decisions have been made using our ideas and suggestions." Another stated that "Thoughts and ideas have been listened to by the development team and acted upon."

\subsection{Uneven adult participation}

Recruiting OA co-creators was challenging due to their lack of understanding of what $\mathrm{PD}$ is and what it might involve. Some initially thought that the workshops would be an extension of the tablet training class that a local NGO offered. Most of the OAs recruited did not have any experience of participating in workshops or meetings as they had mostly fulfilled roles appropriate for rural locations such as being farmers, manual workers, housewives, etc. As such, they lacked confidence in participating, especially in terms of the more technical aspects of the design. A former teacher and a retired engineer were far more confident. Hence participation was at times quite uneven. This uneven participation made us aware of how our design activities need to attend to prior experiences. For example, we used the example of the introduction of fixed phone lines (which some of them experienced), and the way it transformed their lives, to help them imagine what an app on a mobile phone could potentially do. We further sought to address this uneven participation by gradually creating a sense of teamwork, openness, and co-learning. This is captured by a retired farmer, who said,

"I learnt how things develop and how you can put your ideas forward, and people do take notice of you... and I learnt to have more confidence in my own ideas, and I think I learnt a lot about other people."

\subsection{Government and NGO participation}

In terms of the NGO and government staff, while none were familiar with cocreation, they were all familiar with attending meetings and in multi-disciplinary project work. A senior member of the local authority explained that he saw co- 
creation as being very different from how they have traditionally sought to develop services, stating:

"We tend to focus on specific elements when we do focus groups and questionnaires, through [the longitudinal] co-creation we learned a lot from the process about how you can involve people who traditionally would not get involved in using technology or apps, it was very enlightening how they have got involved and how they have developed and co-created the app."

The NGO helped with the recruitment of OAs, and they also took part in co-creation workshops. Recognising that many OAs did not participate, we were reliant on the NGO staff to speak for the 'absent' OAs. The NGO and the government organisation were also organisations that might adopt the resulting co-created service.

\subsection{Participation between workshops}

NGO staff worked together during the week. They had opportunities to discuss the project together and to collectively steer the agenda at subsequent workshops. The academic co-creators had regular contact with the NGO and government staff between workshops as we would frequently visit their offices to interview staff, and at one stage, we had a desk in a shared office. They would feedback on what they thought was important. Further, academic co-creators were the ones that structured the workshops. They would analyse the data emerging from workshop to workshop and set the agenda for the workshops. In contrast, OAs would not see each other between workshops and thus did not have the same opportunities to discuss and collectively steer the agenda.

\subsection{The evaluators' participation}

Before the start of the project, a contract was agreed with the funder specifying the aims and dates for the submission of approximately 40 deliverables. Deliverables were varied and included, ethical agreements, literature reviews, project updates, methodological guidelines and policy developments. They also included the development of the app. Further, the project was required to report on its achievement against the KPIs specified in the contract. The project was allocated a Project Officer whose main role was to organise the reviews of the deliverables and to maintain oversight of the project finances. The funder had well-defined structures and systems in place for the evaluation of projects. Two evaluators were selected (from a bank) by the Project Officer based on their domain expertise. Our experience was that an experienced and less experienced evaluator was selected for each review. Evaluators were paid and most typically had been recipients of previous/current awards. They evaluated each deliverable and whether the project overall was fulfilling its contracted objectives. The project also had two formal reviews which involved a 
face-to-face defence and the submission of a project report. Several members of our project consortium were/had been evaluators for the funder. Consortium members had the experience of writing deliverables for the same funder. Their insights were sought while preparing deliverables for the interim and final review. The interim evaluation resulted in some substantive revisions to deliverables. The final evaluation required a series of minor changes to about a quarter of the deliverables. The final payment was withheld until the revisions were made and revaluated.

What is clear from the above reflective account is that the project consisted of many different lines flowing differently and with very different expectations of future design outcomes, yet they needed to coalesce (or knotted together) for actual and meaningful participation to become possible.

\section{The temporal weaving together of co-responding bundles of participation lines}

In this section, we will draw on the work of Ingold $(1993,2015,2017)$ to provide a reflective analysis of our empirical case study - primarily to illustrate how these ideas might help us think differently about the conditions of possibility for participation in the flow of PD projects. Specifically, we consider how we might make sense of, and conceptualise the weaving together of experiences and imaginations amongst design participants. In Ingold's terms, we examine what might be required for the co-respondence of lines in PD projects that are multistage and involving distributed multi-stakeholder participants. We consider effective participation as the ongoing correspondence (weaving together) of a bundle of flowing participatory lines (each with its own conditionalities, rhythm, tempo, etc.). Here we will focus on three lines (or rather bundles of lines) that emerged as significant: (1) the participants, (2) the project, and (3) the process lines. Of course, there are many more lines that could be considered.

\subsection{Intertwining the participant bundles of lines: the blank piece of paper framing} narrative

A key rationale for undertaking PD is for the process and outcomes to be democratic and inclusive (Huybrechts et al. 2017; Smith et al. 2017). The focus is on seeking out, capturing, and joining together differing perspectives in a final design outcome (Bødker et al. 2017; Ehn 2008) - that is, the creation of genuine participation. We argue that for this to be possible, we need to attend to each participant line and how they co-respond to each other (or not) (Ingold 2015, 2017). Our study highlighted that there were at least four key participant lines (or, more accurately bundles of lines) - (1) the university, (2) the NGO, (3) the local government organisation, and (4) the OAs. Each of these consisted of their own bundles of lines. For example in the university line, there were the project team, the app development team and the university project admin team; in the local government there were a variety of 
departments involved, and the OAs were by no means homogenous, quite the opposite.

What are the necessary conditions for these diverse bundles of lines to correspond in the flow of ongoing PD practices? Clearly, each participant line has its own history and its own imagined future that is brought into design interventions. For coresponding to happen these pasts and imagined futures need to become articulated (or rendered visible) and be allowed to (co)respond to each other for some communality to be co-produced. Let us consider, briefly, the conditionalities and imagined futures of the different participant bundles.

- For the university the project was about research income, research outcomes (publications), the development of an app in line with contractual obligations, amongst others; all to be achieved within the agreed funding timescales.

- For the $N G O s$ the project was about deepening their engagement with their clients, offering more and better services, and becoming more efficient; all of which had to be done as soon as possible with limited and sporadicallyreducing resources.

- For the local government organisation the project was about interacting with their citizens and improving their engagement whilst also cutting costs; all of which had to be done within the planning and financial cycles of the local authority.

- For the $O A s$ the project was about learning about technology, doing something important and interesting, being useful, and much more besides; for some, the project was itself the object and they would like it to continue for as long as possible, others did not quite see the point of it and wanted to move on to do other things.

As is clear from the above, the lines of participation were travelling in very different directions, imagining different outcomes, and with very different temporalities (tempos, rhythms, etc) (Zerubavel 2003). As such, correspondence was not obvious and did indeed not emerge initially. The university, in co-responding to the funder line initially focussed on getting the project going: trying to recruit OAs in South Lakeland, plan specific design encounters, and to develop methods and techniques to facilitate participation at PD workshops. This initial backstage work assumed that the project (and its intended outcomes) would all make sense to the other participants and that it would lead to the development of an app that would be perceived to be beneficial by OAs. However, it soon became evident that such imaginings did not make sense to OA participants. As suggested above, participants live and become their lives/lines based on their previous experiences (Ingold 2015, 2017). In relation to the app, most of our OAs had not used technology in their working lives. Nor did the majority of OAs possess smartphones or have internet access at home. For those that did, there was poor mobile and broadband access. What this meant was that many OAs did not know what an app was, and consequently, they could not imagine what a possible digital service to be co-created might 
be. Nor could they imagine how most of their friends would use any such digital service. It became very evident that co-responding to these biographies and imaginaries (Castoriadis 1997) were an important conditionality for the workshops (and other design interventions) to make sense and become taken as meaningful practices by the OA for them to engage in, as such (Bødker et al. 2017).

Furthermore, the possibilities of a technical outcome to address social isolation did not make sense to them either. For the OA participants, their long-established habitual practices for attending to their social connectedness was through looking at physical notice boards or calling into or phoning an office to find out what is going on - which were themselves practices of social connection. Understood this way, we should not have been surprised that many OAs had quite a negative view of using technology to address their social isolation. They associated it with the closure of desks and phone lines and their replacement with call centres and the internet. For many OAs, the idea that they might participate in a technology-related project, or indeed, a project that they perceived as being potentially harmful, was unlikely. It highlighted how the university imaginaries and the OA participant imaginaries were flowing in very different directions and seemed unlikely to correspond. Similarly, nor could the NGO and the local government participants easily imagine what a possible technological outcome of the project might be, or why it might be important to their futures. Therefore, early on, the participant lines were flowing in different directions bringing with them different conditionalities for responding - that is, imagining different futures, with divergent views of what was meaningful to do in terms of participation in the project. To use the previous metaphor of the conversation: our design conversation not only had different imagined outcomes we had very different starting points and also very different vocabularies.

Making the confluence and correspondence of these lines possible involved creating the conditions of possibility for the OAs to perceive that their participation was possible and meaningful (Ingold 2015, 2017). This involved discussions with a variety of stakeholders outside of the design encounters - backstage (Bødker et al. 2017), as it were. This resulted in the project team adopting the 'blank piece of paper' narrative in order to create the conditions of possibility for meaningful participation. Key to this narrative was to suggest that we were committed to designing solutions (to loneliness and social isolation) that were meaningful to them, whatever form this might take. Whilst we had committed to developing some form of an app as part of the funding application, this was not communicated to the OAs. At this point, we were completely prepared to explore alternative outcomes that were meaningful to them, and defend it to the funders. This 'blank piece of paper' narrative functioned to position the OAs as the experts of their own practices - revealing to them that they had a voice that mattered. In this co-responding we reframed the workshops to consider carefully how OAs practised their social connectedness (their habitual ways of being) - and then surfacing what made such social connecting practices difficult for them. 
As they brought their habitual experiences into the workshop things such as knowing about events, transport, the weather, parking, toilets, benches, and so forth emerged quite quickly. They were skilful in articulating these 'obstacles' to social connectivity (Joshi and Bratteteig 2016; Procter et al. 2014). Understanding these obstacles required a deeper appreciation, by the project team, of their prior experiences that not only precede the design encounters but were already present in design encounters and their imaginaries (Ingold 2016). Members of the project team immersed themselves in some of these practices (such as travelling by bus, finding information of events on notice boards, etc.) to experience 'being in their shoes.' What was needed was a greater attunement with how they imagined their participation, how they imagined what the possible outcomes might be, how such possible outcomes might fit into their daily lives, and so forth. Such appreciation requires processes (such as the 'blank paper' narrative, being in their shoes, interviewing them individually, etc.) which all allowed for joining with them in the flow of their existing practices by listening, watching, and feeling this flow, artfully (Ingold 2017; Karasti and Syrjänen 2004). It became evident that careful attuning, to these prior conditionalities - which they brought into the workshop, implicitly and explicitly-were essential if the outcome of PD was going to be meaningful to the intended user. That is, to attend to the bundles of practices, that are constitutive of their everyday lives, as they live it. Importantly, much of this listening, watching, attuning, etc. happened 'outside' of the actual PD workshops. The workshops became opportunities for the knotting together, in more nuanced ways, some of the correspondences already developed elsewhere.

As the future was being imagined and co-created, correspondingly, it became more and more obvious that a future participant line was missing - that of the longterm hosting partner $(s)$. The university team had sought to co-create an outcome that attended to the practices and imaginaries of OAs. It was assumed that either the government or NGO partner organisation would host the co-created digital service if it was seen as beneficial to OAs. However, when the eventual long-term hosting was explored late in the project, neither organisation had the immediate capacity to host the app. Moreover, both of these organisations had a remarkedly different installed base or infrastructure (technology, organisation, processes, etc.) that made substantially different demands on what the app infrastructure might look like that could potentially accommodate the hosting of the app. Further, as the co-created service intersected the boundaries of different health, social care, government, third sector and private sector organisations, it did not align directly with the focal concerns of a specific organisation or sector as such. This was despite all the organisations recognising the potential benefits of the social connectedness app and being supportive of the project. In short: the design process did not attend to what (Ehn 2008) calls 'design for design after design' (Redström 2008). This raises some important questions in terms of how the long-term hosting participant line might have been included earlier into the flow and knotting together of the other lines. Too early and that line might have become dominant at the expense of the other participants. Too 
late and the knotting together of lines is more difficult as the design process has not attended to the specific conditionalities imposed by the flow of the potential host organisations infrastructure. This conditionality underlines a key element in the knotting together of potentially divergent lines, that of timing. And indeed timing itself requires a nuanced attunement to the conditionalities and temporal qualities of all other lines.

\subsection{Project bundles of lines: knot-working while undergoing the evaluation and the} project

The project bundles of lines refer to the conditioning flows (timeline, process and outcomes) that needed to correspond with the funder line. The funding agreement outlined several necessary correspondences in terms of budgets, timelines, outcomes, etc. Specifically, the funding agreement specified all the interim and final deliverables (including an app) and when these were due. Performance metrics such as new open data-sets, the number of OA participants, and the number of workshops and interviews were also specified in the agreement. As Stirling (2008, p. 276) notes, the interests of funders are secured through the review and reporting processes as they engage in "individual [PD] projects through the formal structures of financing, sponsorship, clientship, patronage, or stakeholder oversight as well as in associated general processes of research governance, disciplinary funding, peer review. " All of these funder conditionalities had a profound influence on the condition of possibilities for the correspondence with other PD lines in the project. For example, for the university line, it was paramount to avoid the revision of deliverables (after interim and final evaluations) as this would incur a substantial cost for the university (Bratteteig and Wagner 2014). Avoiding revisions meant conforming to the funding agreement (and anticipating what reviewers might identify and focus on), yet what was emerging in the flow of the participant bundle of lines was a 'blank piece of paper narrative.' To achieve co-responding flows between the project line and the participant line meant a lot of backstage work was necessary. For example, the university participants had pre-emptive discussions with the project officer about what sort of variance would be acceptable to the funder and how these might be dealt with in terms of the flow of the ever-present evaluation line.

Attuning to the evaluation line was paramount. This attunement meant the project continually underwent the evaluation ('doing in undergoing' it, as Ingold would say). This doing in undergoing the evaluation line animated the project in many different ways as it flowed, continually conditioning its possibilities. Importantly, the specific conditionalities of the flow of the specific evaluators were very important - one might say disproportionately so. However, some of the conditionalities of the flow of this line were invisible. What evaluators might focus on, what they might see as their role, etc. were all important conditionalities. Evaluators were paid outside experts, often motivated to undertake this role in order better to understand how the evaluation process worked to increase their chances of success 
in their future funding applications. It is plausible to anticipate that there were ongoing reviews of project evaluators that took place. It is also plausible to suggest that expert reviewers needed to impress the project officer of the funder as it was the project officer that assigned reviewers as 'independent outsiders.' Central to attuning to the evaluation line (and individual evaluator lines) was the understanding that for the project to be considered successful at both the interim and the final stage, the university, funder and evaluator lines needed to coalesce-yet at least some of the important elements of these flows were more or less invisible.

As the bundles of PD lines flowed - trying to achieve correspondence - the conditioning flow of the project line became more and more dominant due to the scheduled reporting, formal reviews, and deliverable due dates. The pulse and rhythm of this line increasingly shaped the urgency and focus of the design encounters. For example, the OAs were starting to appreciate their involvement and indeed wanted the project to slow down and extend. The project line, in contrast, wanted the participation to speed up and contract-making the co-responding or knotting together of these two lines with very different temporalities very difficult to achieve. As we suggested above this attempt at corresponding happened within the conditionality of the continual undergoing of the evaluation, in what (Brown and Dillard 2015, p. 971) might call a certain "self-discipline in anticipation of negative reactions if they deviate from dominant logics."

The project line, while invisible to some participants, nonetheless continually conditioned the flow of the other lines in terms of the possibilities for the coresponding knotting together, as they flowed. As the flow of the project continued the university team was increasingly preoccupied with ensuring correspondence with the funder and evaluation line. As such, due dates specified for the deliverables tended to condition the issues being discussed as well as the frequency and sequence of the workshops. In a sense all other lines were undergoing the project line, which in turn was undergoing the evaluation line. This figured and configured the shape and form of participation with OAs, NGO and local government participants. OAs were unaware of the timeline and deadlines for deliverables that the project was attentionally co-responding with. The fact that the university team did not reveal these backstage pressures to the OA participants is not because they wanted to deceive them, but rather to maintain a certain openness in the conditions of possibility for corresponding with the flow of the participation lines. As lines flow conditionalities need to be rendered (in)visible to keep open possibilities for mutual learning. This is the work of knot-working, the "rapidly pulsating, distributed, and partially improvised orchestration of collaborative performance between otherwise loosely connected actors..." as Engeström (2008, p. 194) suggests. What this knot-working as the continual undergoing of flows reveals is how the pasts (of all the lines) and the imagined futures (of all the lines) — but in particular the dominant lines (such as the evaluation line) - continually and conditionally shape the 'here and now' of all PD design encounters as they attempt to correspond, whilst flowing. 


\subsection{PD process bundles of lines: the (in)visible conditionalities of the "here and now'}

The process bundles of lines refer to the conditioning flow of the PD methodology and participatory methods, such as workshops, interviews, and probes, etc. This is where the interactional 'here and now' approaches to PD tend to focus - and these flows are important, of course. However, we found that participation in the PD process was not just conditioned by the flow of the other lines, or the PD methods being deployed. Each of the participants had their own biography that shaped their participation more or less significantly. For example, we found that whilst none of the OAs had the experience of being involved in a PD process, several had worked on projects during their professional careers. They tended to be more confident than those that had been farmers or manual workers. What this meant was that the OA individual participant lines varied in how their rememberings (past) and imaginings (imagined futures) conditioned their participation. For example, at one workshop some of the OAs who had professional careers tried to explain the potential benefits of a digital app to the ones who had worked as farmworkers by going back to a common past experience: "do you remember when you first got a telephone at the farm, it was difficult to imagine what use it could be, but you soon discovered that it made your life a lot easier...this is the sort of thing that could happen when you learn how to use an app, it has the same potential to help you even if you cannot see it now." This was a frequent occurrence where participants went back to their own biographies to explain or make sense of what the design practices were trying to achieve, or when they were trying to imagine a different future in which there was an app. This was also true for the NGO and local government participants. Although they were there as a representative of an organisation they nevertheless brought into play their biographies. The key point for Ingold is that we are, in a profound sense, already our biographical lines when we participate. It already conditions what we can or cannot be(come) in the flow of the present here and now design practices.

The PD methods aimed to render visible the views and practices of participants to garner insights and reach correspondence/consensus about design decisions that need to be made throughout the co-creation process. Rendering them visible also provides for opportunities for mutual learning, sharing of expertise, deliberation, experimentation, and design (Bødker et al. 2017; Bratteteig et al. 2013). However, the process of rendering visible is problematic in several ways. First, not all participants can articulate and express, for example, what they need, what they want, and what is desirable (Schmidt 2012). Nevertheless, expressed or not, these conditionalities shaped what was possible to codesign and what not. Second, the biographical lines that the individual participants bring into the design interventions are mostly invisible (even to themselves). As we have already suggested, participants bring their life history and imaginations into the process, yet it tends be visible (to whatever degree) only to those that have followed them longitudinally-i.e. had been in their 'shoes,' as it were. Being in the lifeline of participants requires 
considerable attunement, attention and like-mindedness in the flow of design practices to co-respond. It requires methods that are not just seeking to surface practices, intentions and relational causalities but rather also methods that can allow for the attentional attunement to the subtleties of their life history and their everyday life, as lived (Procter et al. 2014). This suggests the need for biographical methods to inform formal 'design methods' such as 'informal' ethnographic interviews, site visits, participant observation of everyday life, etc. to create the conditions for a more nuanced attunement to the everyday flow (going on) of the participant lines (Titlestad et al. 2009).

These biographical methods, we argue, should focus on researching not only their overt practices but also their rememberings and imaginings. That is, to treat them exactly as biographical lines (flowing from somewhere, going somewhere) rather than just as here and now practitioner participants (i.e. as interacting 'dots'). It also means listening attentively to what is said (and remains unsaid) in the ways participants recall, imagine, listen, make sense, and argue with others. In attunement, attentionality occurs at opportune moments as participants become co-attuned (which does not imply agreement) with each other's rhythms, rememberings and imaginings, which can lead to unexpected correspondences. Indeed, rather than being intentional, surprises, accidents, serendipity divergences and correspondences might better characterise PD processes (Ciborra 1999). There is a risk, in a 'here and now' method focused approach, that these conditionalities remain invisible and that participation becomes 'manufactured' rather than emerging through ongoing attentional attuning or co-responding.

\section{Conclusion and implications for the reorientation of PD}

This paper has argued, with Bødker et al. (2017) and others, that the existing literature on participation tends to focus on frontstage design interactions (participants, methodologies and methods) to facilitate PD 'here and now' - what we called the interactional approach. In contrast, we located ourselves in an evolving literature that argues for an approach that is temporally more longitudinal and that attends to both the frontstage and backstage within an extended temporal frame, what we called the transformational approach (Bødker et al. 2017) - an approach we see as complimentary to the interactional approach. Specifically, we turned to the concepts and vocabulary of the social anthropologist Tim Ingold $(1993,2011,2015,2017)$ to add to this transformational PD literature. We argue that to enact transformation PD we need to shift our gaze from what is in front of us 'here and now' (the frontstage design interactions) to the conditioning flow of other relevant bundles of lines (backstage) already animating or framing what is possible in the frontstage. Further, still, we also need to shift our gaze orthogonally, to see that each line has its own biography flowing from somewhere and heading somewhere, which is conditioning its possibilities for participation in particular ways. We suggested that we need to take PD as being enacted in and through a multiplicity of co-responding lines-with 
different temporalities and different attentionalities - that not only join together but also differentiate to enact PD practices as exactly that. Moreover, PD is not just about the development of consensus or sameness, it is also, and importantly, about difference or differentiation. That is, the knotting together of different stories rather than the creation of one story.

Conceptualising of PD as corresponding bundles of lines, as they flow rather than focussing on the 'here and now' participants/practices leads us to three concrete implications for future studies and interventions to consider (as depicted in Figure 2).

A first implication relates to broadening our design focus from here/now workshop participation practices to conditioning storylines. To bring the flowing bundles of lines into the PD workshop (methods/practices) is to reanimate their (hi)stories, or simply, to tell stories - "every line is a story" (Ingold 2015, p. 168). Enclosed in every 'participant,' 'practice,' etc. there is a story of how they became what they are 'here and now,' and where they are heading. Therefore, what is interesting about them is not so much what they currently are in the 'here and now' (as actors with attributes) as in their unfolding as storylines - their contingent histories and conditioned directionalities along which they have grown and carry on transforming. That is why we do not simply read the last pages of stories. As ongoing life stories (biographies one might say), their past and their future are already present in the flow of every design encounter-animating it, as rememberings and imaginings, silently working to condition what is possible to do say and think. Indeed, each line in the PD workshop has its own conditioning flow of action and temporalities, and its own serendipity, always and already animating it in more or less significant ways - yet not 'present' in the workshop as such.

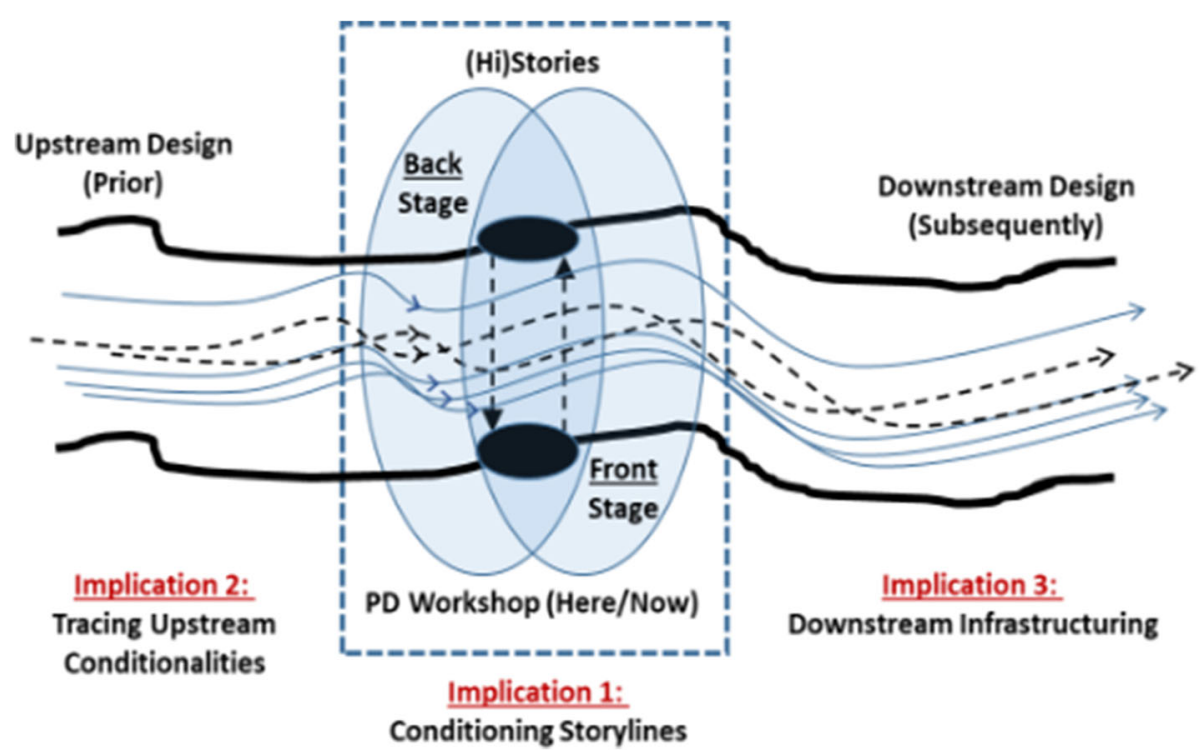

Figure 2. The three flows of transformational PD 
If this is the case, how do we bring these life stories (or biographies) into the PD practices, concretely? We would suggest, for example, that we do not only need participants as exemplars of certain personas, we also need the stories that animate these participants (and by implication personas). Rather than asking them directed questions like 'who are you and what do you want to get from this process/project,' we should rather ask 'tell us your story and your hopes for the future.' Moreover, when we investigate participant practices we do not ask 'how do you do x or y'? We should rather ask, 'how did it come about that you do $\mathrm{x}$ or $\mathrm{y}$ in this manner,' thus eliciting a story rather than an answer. We also need to appreciate that frontstage design practices are animated by mostly invisible backstage flows. For example, how the evaluation line animated the design workshops, conditioning what is (im)possible to do. This storyline orientation requires PD practitioners to develop different sensibilities away from analysis towards attunement with the temporal unfolding of storylines. Some examples of such sensibilities are:

- To always keep the horizon open or on the move for as long as possible, as any good story does. That is to endeavour never to settle the design narrative and practices (data collection, analysis, etc) too quickly on assumed important human or technological actors (or logics) made present through our techniques of analysis (use cases, personas, etc). For example, adopting the 'blank piece of paper' narrative kept open the horizon of possibility for a story to develop in our project. Of course, as we suggested, there is also the element of timing. At some point some decisions need to be made at the appropriate time in order to keep correspondence with other lines. Hence the importance of being attuned to the temporalities of all relevant lines.

- To always also reveal (hi)stories (or biographies) not just instances. For any given practice/participant retrace the history and directionality that constitute that particular storyline. For example, if we had traced the stories of our participants more closely we would not have framed the initial workshops in terms of a technological outcome, which initially reduced the possibilities for participation.

- Understand the temporalities of every storyline. Explore important rhythms, tempos, urgencies, timings, etc. that condition the flow of the storylines. For example, we were surprised as to how important planning ahead was for the OAs (who seem to have a lot of time available). Yet, they were deeply dependent on other cycles and rhythms (such as bus schedules, event schedules, and so forth), hence their seemingly contradictory emphasis on planning ahead.

- Explore how the flow of the invisible backstage lines already condition or animate the relevant lines present in the workshop; for example, how were we unwittingly framing and enacting the workshops due to the way the evaluation line was already animating the possibilities to think, act and imagine.

A second implication relates to a move upstream to understand conditionalities. Thinking of flowing lines that need to co-respond requires that we understand the conditionalities that every line brings into the participation 'here and now.' In other 
words, prior to any intervention we also need to shift our attention to the participants' histories - prior experiences, manners of doing, etc. - that already shape the necessary conditions for correspondence 'here and now' to become taken as meaningful or even possible. In a sense PD practitioners need to move upstream and design the conditions of possibility for PD to become realisable - that is, to design the possibility of design before we design (Redström 2008). Practically this means, for example, to:

- For each line, trace them upstream to understand the conditionalities (possibilities, constraints, etc.) that they might bring into the PD event that might make correspondence possible or more difficult to achieve. For example, we did not appreciate what we needed to attend or attune to as well as do before the workshops to make the workshops a meaningful encounter of lines (given their very different biographies). If we were more aware of where the participants were coming from we would have designed the design interventions very differently. For example, starting the design process more where the participants were rather than where we were (but that assumed that we knew where they were, which we did not).

- Appreciate all the necessary lines needed to actualise PD as genuine PD here and now. Existing literature has already identified some of these conditioning lines, such as methods, participants, commensurable languages, design spaces, and so forth. For each of these lines, we need to understand how they are situated relative to each other and how they condition what is (not) possible. For example, our design language was configured by the funding proposal, the participant's design language was configured by the experience of loneliness - these languages were in many respects incommensurable and we were not sufficiently aware of this, initially.

A third implication pertains to a move downstream to do infrastructuring. The outcomes of design interventions will continue to flow downstream. They will need to coalesce with other flows, flows which might have become stable (even immutable). How can we design to design after design? These are some of the issues that 'infrastructuring' literature wants us to take note of. How do we ensure that outcomes can cope with the future demands for coalescing that they might encounter? Practically this means, for example, to:

- Appreciate where the lines might flow towards and what sort of conditionalities they will be bringing into the world of practice, where they will need to co-respond to remain vibrant and flowing. This is especially important in multi-stakeholder, multi-staged design that takes place over an extended period. In our project, we missed this perspective entirely. We assumed a certain future for how the app would be hosted which was not possible. This threatened the sustainability of the design outcomes.

- Trace downstream possibilities and endeavour to understand the conditionalities (possibilities, constraints, etc.) that they might be demanded of the design 
interventions. Configure the relevant conditionalities to make future correspondence and flow more likely. For example, had we appreciated the importance of infrastructuring we might have written the funding proposal differently by including the potential future host of outputs into the very design of the project.

There is a lot more we could say. The above suggestions are indicative and illustrative of what this reorientation towards understanding PD as the knotting together of flowing lines might mean. Importantly, what we are suggesting is that to do transformative PD is not to do radically different things from what we normally do in interactional PD. It is rather that we do the same things (workshops, methods, etc.) but do them very differently. We still have workshops with use cases, personas, etc. However, we will understand and think of these in different terms; in terms of storylines (coming from somewhere and going somewhere), in terms of conditionalities (prior experiences, concerns, imaginaries, etc.), in terms of timings (different timeframes, speeds, rhythms, etc.), and in terms of knotting (attending to, attuning or co-responding, etc.). In the end, we do not need to get some form of participation going, as such-life is always on the move, always already happening. What it is needed is an approach that can do co-responsive knot-working, for flowing lives to become entwined without becoming one; to co-respond with storylines that are already flowing, onwards and to elsewhere. Only through such a grasping of the flow, as it happens, can participants become involved in their own becoming - a requirement for participatory design to recover its truly democratic ideals rather than being a technology to engineer consensus and agreement (Cooke and Kothari 2007).

\section{Acknowledgements}

We want thank AgeUK South Lakeland, South Lakeland District Council and our participants for the patience and contribution to an evolving storyline. This research was made possible with funding from the European Union's Horizon 2020 research and innovation programme under Grant No.:693319.

Open Access This article is licensed under a Creative Commons Attribution 4.0 International License, which permits use, sharing, adaptation, distribution and reproduction in any medium or format, as long as you give appropriate credit to the original author(s) and the source, provide a link to the Creative Commons licence, and indicate if changes were made. The images or other third party material in this article are included in the article's Creative Commons licence, unless indicated otherwise in a credit line to the material. If material is not included in the article's Creative Commons licence and your intended use is not permitted by statutory regulation or exceeds the permitted use, you will need to obtain permission directly 
from the copyright holder. To view a copy of this licence, visit http:// creativecommons.org/licenses/by/4.0/.

\section{References}

Balka, Ellen (2010). Broadening discussion about participatory design: A reply to Kyng. Scandinavian Journal of Information Systems, vol. 22, no. 1, pp. 77-84.

Bannon, Liam; Jeffrey Bardzell; and Susanne Bødker (2018). Reimagining participatory design. Interactions, vol. 26, no. 1, pp. 26-32.

Björgvinsson, Erling; Pelle Ehn; and Per-Anders Hillgren (2010). Participatory design and 'democratizing innovation'. In PDC '10: Proceedings of the 11th Biennial Participatory Design Conference, Sydney, Australia, 29 November, 2010- 3 December, 2010. New York, NY, USA: ACM Press, pp. 41-50.

Bødker, Susanne (2015). Third-wave HCI, 10 years later-participation and sharing. Interactions, vol. 22 , no. 5, pp. 24-31.

Bødker, Susanne; and Morten Kyng (2018). Participatory design that matters-Facing the big issues. ACM Transactions on Computer-Human Interaction, vol. 25, no. 1, pp. 1-31.

Bødker, Susanne; Christian Dindler; and Ole Sejer Iversen (2017). Tying knots: Participatory infrastructuring at work. Computer Supported Cooperative Work (CSCW), vol. 26, no. 1-2, pp. 245-273.

Bratteteig, Tone; and Ina Wagner (2014). Disentangling participation: Power and decision-making in participatory design. New York: Springer International Publishing.

Bratteteig, Tone; and Ina Wagner (2016). Unpacking the notion of participation in participatory design. Computer Supported Cooperative Work (CSCW), vol. 25, no. 6, pp. 425-475.

Bratteteig, Tone; Keld Bødker; Yvonne Dittrich; Preben Holst Mogensen; and Jesper Simonsen (2013). Methods: Organising principles and general guidelines for participatory design projects. Routledge International Handbook of Participatory Design, pp. 117-144.

Brown, Judy; and Jesse Dillard (2015). Dialogic accountings for stakeholders: On opening up and closing down participatory governance. Journal of Management Studies, vol. 52, no. 7, pp. 961985.

Castoriadis, Cornelius (1997). The imaginary institution of society. (K. Blamey, Trans.). Cambridge \& Malden, MA: Polity Press.

Ciborra, Claudio U. (1999). Notes on improvisation and time in organizations. Accounting, Management and Information Technologies, vol. 9, no. 2, pp. 77-94.

Cooke, Bill; and Uma Kothari (2007). Participation: the new tyranny? London: Zed Books.

Crabu, Stefano; and Paolo Magaudda (2018). Bottom-up infrastructures: Aligning politics and technology in building a wireless community network. Computer Supported Cooperative Work (CSCW), vol. 27, no. 2, pp. 149-176.

Dewey, John (2004). Democracy and education. Courier Dover Publications.

Dittrich, Yvonne; Annelie Ekelin; Pirjo Elovaara; Sara Eriksen; and Christina Hansson (2003). Making e-government happen everyday co-development of services, citizenship and technology. In HICSS '03: Proceedings of the 36th Annual Hawaii International Conference on System Sciences, Big Island, Hawaii, 6 - 9 January 2003. NW Washington, DC: IEEE, pp. 12 pp.

Druin, Allison; and Carina Fast (2002). The child as learner, critic, inventor, and technology design partner: An analysis of three years of Swedish student journals. International Journal of Technology and Design Education, vol. 12, no. 3, pp. 189-213.

Edwards, Anne (2010). Being an expert professional practitioner. Dordrecht: Springer Netherlands. 
Ehn, Pelle (2008). Participation in design things. In PDC '08: Proceedings of the Tenth Anniversary Conference on Participatory Design, Bloomington, Indiana, 1 October, 2008- 4 October, 2008. Indianapolis, USA: Indiana University Press, pp. 92-101. Accessed 8 January 2021.

Engeström, Yrjö (2008). From teams to knots: Activity-theoretical studies of collaboration and learning at work. Cambridge: Cambridge University Press.

Gaver, Bill; Tony Dunne; and Elena Pacenti (1999). Design: Cultural probes. Interactions, vol. 6, no. 1, pp. 21-29.

Huybrechts, Liesbeth; Henric Benesch; and Jon Geib (2017). Institutioning: participatory design, codesign and the public realm. CoDesign, vol. 13, no. 3, pp. 148-159.

Ingold, Tim (1993). The temporality of the landscape. World Archaeology, vol. 25, no. 2, pp. 152 174.

Ingold, Tim (2007). Lines: a brief history. London ; New York: Routledge.

Ingold, Tim (2011). Being alive: essays on movement, knowledge and description. London: Routledge.

Ingold, Tim (2015). The life of lines. Milton Park, Abingdon, Oxon ; New York, NY: Routledge.

Ingold, Tim (2017). On human correspondence. Journal of the Royal Anthropological Institute, vol. 23, no. 1, pp. 9-27.

Jensen, Casper Bruun; and Brit Ross Winthereik (2013). Monitoring movements in development aid: Recursive partnerships and infrastructures. MIT Press.

Joshi, Suhas; and Tone Bratteteig (2016). Designing for prolonged mastery. On involving old people in participatory design. Scandinavian Journal of Information Systems, vol. 28, no. 1, pp. 3-36.

Karasti, Helena (2014). Infrastructuring in participatory design. In PDC '14: Proceedings of the 13th Participatory Design Conference: Research Papers, Windhoek, Namibia, 6 - 10 October, 2014. New York: ACM Press, pp. 141-150.

Karasti, Helena; and Jeanette Blomberg (2018). Studying infrastructuring ethnographically. Computer Supported Cooperative Work (CSCW), vol. 27, no. 2, pp. 233-265.

Karasti, Helena; and Anna-Liisa Syrjänen (2004). Artful infrastructuring in two cases of community PD. In PDC '04: Proceedings of the eighth conference on Participatory design Artful integration: interweaving media, materials and practices, Toronto, Canada, 27 - 31 July 2004. New York, NY, USA: ACM Press, pp. 20.

Karasti, Helena; Karen S. Baker; and Florence Millerand (2010). Infrastructure time: Long-term matters in collaborative development. Computer Supported Cooperative Work (CSCW), vol. 19, no. 3, pp. 377-415.

Kensing, Finn (2003). Methods and practices in participatory design. Copenhagen: ITU Press.

Kensing, Finn; and Jeanette Blomberg (1998). Participatory design: Issues and concerns. Computer Supported Cooperative Work (CSCW), vol. 7, no. 3-4, pp. 167-185.

Latour, Bruno (2005). Reassembling the social: an introduction to actor-network-theory. Oxford; New York: Oxford University Press. .

Loi, Daria (2007). Reflective probes, primitive probes and playful triggers. Ethnographic Praxis in Industry Conference Proceedings, vol. 2007, no. 1, October 2007, pp. 232-245.

Manning, Erin (2016). The minor gesture. Durham London: Duke University Press.

Marshall, Judi (1999). Living life as inquiry. Systemic Practice and Action Research, vol. 12, no. 2, pp. 155-171.

Marshall, Judi; and Peter Reason (2007). Quality in research as "taking an attitude of inquiry". Management Research News, vol. 30, no. 5, pp. 368-380.

Martin, David; John Mariani; and Mark Rouncefield (2009). Practicalities of participation: Stakeholder involvement in an electronic patient records project. In M. Büscher, R. Slack, M. Rouncefield, R. Procter, M. Hartswood, and A. Voss (Eds.), Configuring User-Designer Relations. London: Springer London.

McIntyre, Alice (2007). Participatory action research. SAGE Publications. 
Mikalsen, Marius; Babak A. Farshchian; and Yngve Dahl (2018). Infrastructuring as ambiguous repair: A case study of a surveillance infrastructure project. Computer Supported Cooperative Work (CSCW), vol. 27, no. 2, pp. 177-207.

Muller, Michael J (2002). Participatory design: The third space in HCI. In A. Sears and J. A. Jacko (Eds.), The Human-Computer Interaction Handbook: Fundamentals, Evolving Technologies and Emerging Applications,. New York: Lawrence Erlbaum.

Neumann, Laura J; and Susan Leigh Star (1996). Making infrastructure: The dream of a common language. In PDC'96: Proceedings of the Fourth Biennial Participatory Design Conference, Cambridge, MA, USA, 13-15 November 1996. Palo Alto, CA: Computer Professionals for Social Responsibility, pp. 231-240.

Nolte, Alexander; and Thomas Herrmann (2016). Facilitating participation of stakeholders during process analysis and design. In A. De Angeli, L. Bannon, P. Marti, and S. Bordin (Eds.), COOP 2016: Proceedings of the 12th International Conference on the Design of Cooperative Systems, 2327 May 2016, Trento, Italy: Springer International Publishing, pp. 225-241.

Parmiggiani, Elena (2017). This is not a fish: On the scale and politics of infrastructure design studies. Computer Supported Cooperative Work (CSCW), vol. 26, no. 1, pp. 205-243.

Procter, Rob; Trisha Greenhalgh; Joe Wherton; Paul Sugarhood; Mark Rouncefield; and Sue Hinder (2014). The day-to-day co-production of ageing in place. Computer Supported Cooperative Work (CSCW), vol. 23, no. 3, pp. 245-267.

Redström, Johan (2008). RE:Definitions of use. Design Studies, vol. 29, no. 4, pp. 410-423.

Robertson, Toni; and Jesper Simonsen (2012). Participatory Design: an introduction. In Routledge International Handbook of Participatory Design. New York: Routledge.

Schmidt, Kjeld (2012). The trouble with 'tacit knowledge'. Computer Supported Cooperative Work (CSCW), vol. 21, no. 2, pp. 163-225.

Shapiro, Dan (2005). Participatory design: the will to succeed. In CC '05: Proceedings of the 4th decennial conference on Critical computing between sense and sensibility, Aarhus, Denmark, 20 24 August, 2005. New York, NY, USA: ACM Press, pp. 29.

Simonsen, Jesper; and Toni Robertson (2012). Routledge international handbook of participatory design. New York: Routledge.

Smith, Rachel Charlotte; Claus Bossen; and Anne Marie Kanstrup (2017). Participatory design in an era of participation. CoDesign, vol. 13, no. 2, pp. 65-69.

Star, Susan Leigh; and Karen Ruhleder (1996). Steps toward an ecology of infrastructure: Design and access for large information spaces. Information Systems Research, vol. 7, no. 1, pp. 111-134.

Stirling, Andrew (2006). Analysis, participation and power: justification and closure in participatory multi-criteria analysis. Land Use Policy, vol. 23, no. 1, pp. 95-107.

Stirling, Andy (2008). "Opening up" and "closing down": Power, participation, and pluralism in the social appraisal of technology. Science, Technology, \& Human Values, vol. 33, no. 2, pp. 262-294.

Suchman, Lucy (2002). Located accountabilities in technology production. Scandinavian Journal of Information Systems: Special issue on Ethnography and Intervention, vol. 14, no. 2, pp. 91-105.

Suchman, Lucy (2009). Human-machine reconfigurations: plans and situated actions. Cambridge New York Melbourne Madrid Cape Town Singapore São Paulo Delhi Daubei Tokyo Mexico City: Cambridge University Press.

Taylor, Claire; Min Wilkie; and Judith Baser (2006). Doing Action Research: A Guide for School Support Staff. London: SAGE.

Titlestad, Ola; Knut Staring; and Jorn Braa (2009). Distributed development to enable user participation: Multilevel design in the HISP network. Scandinavian Journal of Information Systems:, vol. 21, no. 1, pp. 27-50.

Whittle, Jon (2014). How much participation is enough? A comparison of six participatory design projects in terms of outcomes. In PDC '14: Proceedings of the 13th Participatory Design 
Conference: Research Papers, Windhoek, Namibia, 6 - 10 October, 2014. New York, NY, USA: ACM Press, pp. 121-130.

Zerubavel, Eviatar (2003). Time maps: collective memory and the social shape of the past. Chicago, Ill: University of Chic'ago Press.

Publisher's Note Springer Nature remains neutral with regard to jurisdictional claims in published maps and institutional affiliations. 